\title{
Método alternativo de germinación para determinar la calidad de semillas en Buffel Grass (Cenchrus ciliaris L.)
}

\author{
Agüero, C.G; G.R. Pereyra y R.O. Rolando
}

\begin{abstract}
RESUMEN
Un problema que surge al evaluar la calidad fisiológica en Cenchrus ciliaris L. es el bajo porcentaje de germinación obtenido en los ensayos del ISTA debido a que la dormición en las semillas no es eliminada eficazmente con los pretratamientos indicados. El objetivo de este trabajo fue desarrollar un método de análisis que permitiera determinar de manera más precisa la calidad de la semilla en $C$. ciliaris $\mathrm{L}$. Se utilizaron semillas recién cosechadas del cultivar Texas. Los ensayos se extendieron por 6 meses, con intervalos de 3 meses entre cada uno. Se determinó la relación porcentual de fascículos llenos y la viabilidad por tetrazolio. En los ensayos de germinación se utilizaron diferentes alternativas de preparación de las semillas: fascículos intactos, fascículos escarificados, cariópsides intactas y cariópsides escarificadas. Se evaluó la evolución de la dormición en el tiempo (0, 3 y 6 meses) y la ruptura de ésta con diferentes tratamientos (testigo, frío, calor, $\mathrm{KNO}_{3}$ y $\mathrm{AG}_{3}$ ). Para determinar la calidad fisiológica en $C$. ciliaris $L$. es recomendable la utilización de cariópsides escarificadas y el tratamiento con ácido giberélico.
\end{abstract}

Palabras clave: dormición, cariópside, pretratamientos.

Agüero, C.G; G.R. Pereyra and R.O. Rolando 2017. Alternative germination method to determine the quality of seeds in Buffel Grass (Cenchrus ciliaris L.).Agriscientia 34: 47-58

\section{SUMMARY}

One problem in assessing the physiological quality Cenchrus ciliaris L. are low germination percentages obtained in ISTA tests because dormancy in seeds is not eliminated effectively with the recommended pre-treatments. The aim of this work was to develop a protocol of analysis to determine more accurately seed quality in C. ciliaris L. Freshly harvested seeds of the cultivar Texas were used. The tests were conducted for 6 months at intervals of 3 months between each. The ratio between full and empty florets and viability were determined by tetrazolium. In the germination tests different alternative seeds were used: intact fascicle, scarified fascicle, intact cariopses and scarified ones. The evolution of dormancy in time (0, 3, 6 months) and its breakdown with different treatments (control, cold, heat, $\mathrm{KNO}_{3}$ and $\mathrm{GA}_{3}$ ) were evaluated. In order to determine the 
physiological quality in C. ciliaris L. it is advisable to use scarified cariopses and gibberellic acid treatment.

Keywords: dormancy, cariopse, pre-treatments.

C.G. Agüero, G. R. Pereyra y R. O. Rolando: Laboratorio de Semillas (LASIDYS), Facultad de Ciencias Agropecuarias, Universidad Nacional de Córdoba. Ing. Agr. Félix Aldo Marrone 746, Ciudad Universitaria, 5000, Córdoba, Argentina. Correspondencia a: aguerocesar@agro.unc.edu.ar

\section{INTRODUCCIÓN}

La calidad de las semillas en especies como Buffel Grass (Cenchrus ciliaris L.) es un factor condicionante al momento de realizar la siembra para implantar la pastura y frecuentemente está asociada con la madurez, la dormición y el deterioro que ocurre en el almacenamiento (Clements \& Cameron, 1980). Conocer los atributos de calidad es indispensable para alcanzar la productividad deseada.

Desde el punto de vista fisiológico la calidad está representada por la capacidad de las semillas para desempeñar funciones vitales y puede ser evaluada mediante la germinación, la viabilidad, el vigor y la longevidad.

Según Baskin \& Baskin (1989) una semilla viable que no germina bajo ningún tipo de condición ambiental normal, es una semilla durmiente. La dormición ha sido descripta como una característica adaptativa que hace que una semilla germine en un tiempo y lugar favorable para el desarrollo de una planta (Pelton, 1952).

En el caso específico de $C$. ciliaris L., la etapa de dormición está determinada por un período comprendido entre los 16 a los 20 meses desde la cosecha, y disminuye durante el almacenamiento (Namur et al., 2014).

De acuerdo al esquema de Nikolaeva (1977), actualizado y descripto por Baskin \& Baskin (2004), los tipos de dormición que pueden exhibir las semillas son: morfológica, fisiológica, morfofisiológica, física y combinada (física y fisiológica). Los distintos tipos responden a características inherentes a las semillas como la permeabilidad de las cubiertas seminales, el estado de desarrollo en que se encuentra el embrión y el estado fisiológico embrional (Baskin \& Baskin, 1989).
La dormición física es causada por capas de células impermeables al agua en las cubiertas seminales o en la pared de los frutos. La ruptura de la dormición ocurre en estas semillas mediante la apertura de un orificio natural o artificial por el cual el agua ingresa al embrión (Baskin et al., 2000).

En semillas con dormición combinada, la semiIla (o fruto) es impermeable al agua y además el embrión se encuentra fisiológicamente dormido. En la mayoría de los casos el componente fisiológico hallado es poco profundo (Baskin \& Baskin, 1998).

En C. ciliaris L. las características morfológicas pueden ser las responsables de inhibir la germinación; un ejemplo de ello es la dureza observada en las cubiertas de protección las cuales se incrementan con la cantidad de luz recibida y con la actividad fotosintética. Alternativamente, distintos tipos de fenoles inhibidores de la germinación pueden variar con la irradiación total (Sharif-Zadeh \& Alistair Mordoch, 2000).

La influencia que ejercen las cubiertas que protegen a las semillas como lemmas y páleas, se agrupan en: restricción mecánica a la germinación, modificación del requerimiento de luz del embrión, presencia de inhibidores que interfieren la germinación, prevención de la entrada de agua y obstáculo en el intercambio gaseoso (Bewley \& Black, 1982).

Además de la participación de las estructuras de protección en la dormición, las semillas poseen un importante rol en el impedimento de la germinación. El cariópside fruto encontrado únicamente en Poaceae es seco, monospérmico e indehiscente. Su pericarpio varía en dureza y grado de adherencia a la cubierta seminal (Sendulsky et al., 1986). Tanto el pericarpio como la testa, estructuras del cariópside, afectan la emergencia de los embrio- 
nes en semillas con dormición (Werker, 1981). Hay evidencia que la punción de la cubierta seminal, particularmente en la región cercana al embrión, promueve la germinación en semillas durmientes (Simpson, 1990).

Según Loch (1993) la germinación más rápida y completa de las cariópsides se debe a la absorción de agua en ausencia de las cubiertas que constituyen el fascículo. Parihar \& Kanodia (1984) no descartan la acción de fenoles en las cubiertas como las causantes del retraso de germinación, aunque según Murdoch \& Ellis (2000) los componentes que provocan la dormición son propios de las cariópsides más que de las estructuras que lo rodean.

La dormición se puede eliminar exponiendo las semillas a distintas condiciones cuando se realizan ensayos de germinación en laboratorio. Se han obtenido estímulos en semillas de Buffel Grass utilizando el preenfriamiento (prechilling) (Andersen, 1953), el presecado (predrying) (Brown, 1952; Andersen, 1953; Butler, 1985) y el desglumado (Andersen, 1953; Watson, 1955).

Según Butler (1985) el humedecimiento con nitrato de potasio no fue favorable como promotor y el preenfriamiento tuvo efectos negativos; resultados similares respecto a bajas temperaturas fueron expresados por Hacker (1989). El nitrato de potasio es efectivo para promover la germinación en semillas de pastos con dormición actuando en la vía pentosa monofosfato, importante en las etapas tempranas de la germinación (ISTA, 2009).

Las Reglas Internacionales de Análisis de Semillas (ISTA, 2012) brindan criterios generales para la superación de la dormición en distintas especies, muchas de ellas pertenecientes a la familia Poaceae. Dichos procedimientos deben ser aplicados adicionalmente al test de germinación estándar si la dormición está afectando al lote de semillas. Los tratamientos de ruptura prescriptos para cada especie no excluyen que otros procedimientos, también incluidos en ISTA, puedan ser utilizados.

Los métodos que ISTA (2012) propone para romper dormición fisiológica son: pretratamiento frío, pretratamiento calor, almacenaje en seco, fotoperiodo, envoltura de las semillas en recipientes de polietileno, ácido giberélico, nitrato de potasio, escarificación ácida y escarificación mecánica. Para dormición causada por cubiertas impermeables indican el remojo, la escarificación mecánica y la escarificación ácida. Por otra parte, para dormición debida a sustancias inhibitorias, el prelavado y la remoción de estructuras que rodean a las semillas son técnicas aconsejadas.

Específicamente en $C$. ciliaris L. son tres las me- todologías que sugiere ISTA para superar la dormición el pretratamiento frío, el pretratamiento calor y el tratamiento con nitrato de potasio.

Al hacer una revisión de los métodos específicos de ruptura de dormición recomendados por las normas internacionales en $C$. ciliaris $L$., y teniendo en cuenta que la definición de semilla pura expresada por las normas incluye tanto a fascículos (con o sin cariópsides en su interior) como a cariópsides individuales desprendidas de su estructura de dispersión natural, surgen los interrogantes: ¿serán los tratamientos de ruptura de dormición recomendados por ISTA igualmente efectivos tanto para fascículos como para cariópsides?; ¿cómo responderán algunos de los tratamientos adicionales recomendados en las normas para C. ciliaris L.?; ¿es conveniente al expresar la calidad física tener en consideración el porcentaje de fascículos llenos?; ¿de qué manera y con qué precisión contribuye directa o indirectamente, el ensayo de viabilidad por tetrazolio al ensayo de germinación?.

Se plantea como hipótesis que la aplicación de un nuevo método alternativo de análisis al utilizado por ISTA permitirá determinar de manera más precisa la calidad de semillas de Buffel Grass.

Debido a que no se han encontrado evidencias en $C$. ciliaris $L$. del efecto del escarificado en fascículos (unidad de dispersión) como en semillas (cariópsides) y que dichas técnicas adicionales pueden ser tomadas en cuenta para romper dormición, se delinearon los siguientes objetivos:

Determinar la metodología de germinación que mejor exprese la calidad fisiológica de la semilla, considerando las siguientes alternativas:

1) Evaluar el efecto de los tratamientos de preparación de las semillas sobre la germinación.

2) Evaluar los tratamientos para superar la dormición en semillas.

3) Evaluar la evolución de la dormición de las semillas en los primeros seis meses de almacenamiento.

\section{MATERIALES Y MÉTODOS}

Se utilizó semilla de Buffel Grass del cultivar Texas cosechada durante el mes de marzo del año 2014 en la Estación Experimental INTA Deán Funes, provincia de Córdoba, Argentina. Las mismas se extrajeron manualmente cuando la especie alcanzó la madurez suficiente y antes que los fascículos se desprendan de la planta madre. El material recolectado estuvo compuesto por fascículos, unidad de dispersión natural de C. ciliaris L. 
Las pruebas se iniciaron a 5 días de realizada la cosecha y se extendieron por un plazo de 6 meses, con intervalos de 3 meses entre ensayos, siendo de esta manera tres los momentos de evaluación (0, 3 y 6 meses).

Las condiciones para los ensayos de germinación se obtuvieron del protocolo descripto por las reglas internacionales ISTA (2012). La temperatura fue alterna $20<=>30^{\circ} \mathrm{C}$, correspondiendo la temperatura baja al ciclo de noche (16 horas) y la alta al ciclo de día (8 horas). El sustrato de germinación usado fue TP (sobre papel). Las repeticiones fueron sembradas en bandejas de plástico con una proporción de $35 \mathrm{ml}$ de agua por gramo de papel; luego se colocaron dentro de bolsas de polietileno para evitar pérdida de humedad. Se aplicaron los tratamientos de ruptura de dormición indicados para C. ciliaris L. por las reglas ISTA (2012) y los propuestos en los experimentos de esta investigación.

Los conteos de plántulas normales se realizaron a los 7 y 28 días según lo recomendado por las normas y para evaluar el progreso de la germinación a través del tiempo se efectuaron conteos intermedios a los 14 y 21 días. Al final de los ensayos los valores de cada uno de los conteos fueron sumados y expresados como porcentaje de germinación (poder germinativo). Se utilizaron cuatro repeticiones de 25 semillas para cada tratamiento. Las semillas se desinfectaron con una solución de hipoclorito de sodio al $1 \%$ y luego enjuagadas con abundante agua destilada para eliminar residuos de la solución.

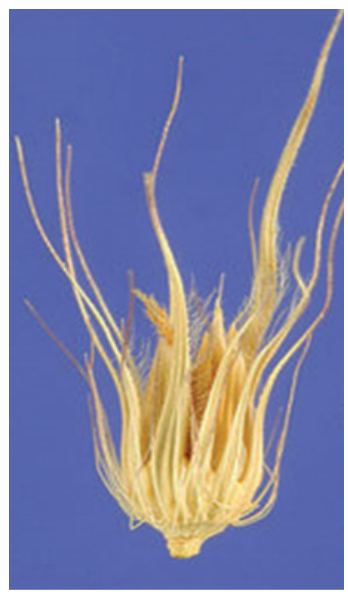

a b

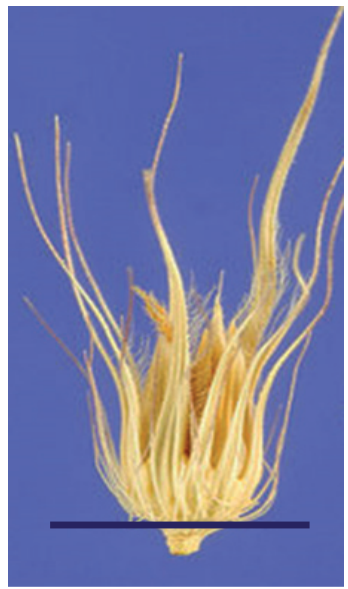

Se consideraron dos aspectos principales que responden a los objetivos fijados para este trabajo

1) Alternativas de preparación de las semillas para el análisis de germinación.

Se utilizaron cuatro tipos de preparaciones o materiales.

a- Fascículos intactos (F) (Testigo) (indicado en normas ISTA)

b- Fascículos escarificados (FE)

c- Cariópsides intactas (C)

d- Cariópsides escarificadas (CE)

El escarificado de fascículos se realizó mediante un corte transversal completo en la región basal y proximal de la inserción, sitio donde se localizan los cariópsides con cuidado de no dañarlos. En cariópsides, el escarificado se efectuó con aguja en la región distal del fruto-semilla de manera de evitar daños en la zona embrionaria (Figura 1 y 2).

2) Alternativas de pretratamientos para ruptura de la dormición.

- Testigo: fascículos y las cariópsides fueron sembrados sin pretratamiento.

- Pretratamiento frío: temperatura de 5 a $10{ }^{\circ} \mathrm{C}$ durante 7 días (ISTA, 2012).

- Pretratamiento calor: temperatura de $35^{\circ} \mathrm{C}$ durante 7 días (ISTA, 2012).

- Nitrato de potasio $\left(\mathrm{KNO}_{3}\right)$ : sustrato de germinación humedecido con una solución de $\mathrm{KNO}_{3}$ al 0,2\% (ISTA, 2012).

- Ácido giberélico $\left(\mathrm{AG}_{3}\right)$ : se humedeció el sustrato con una solución de ácido giberélico al 0,05\%.

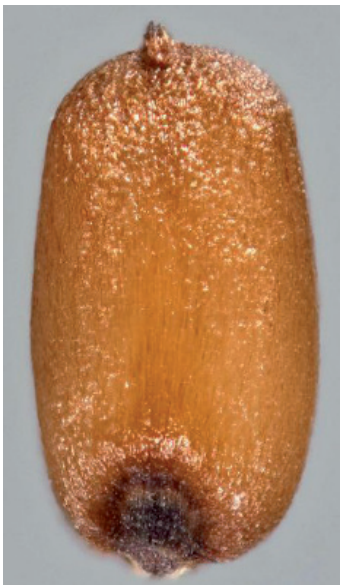

C

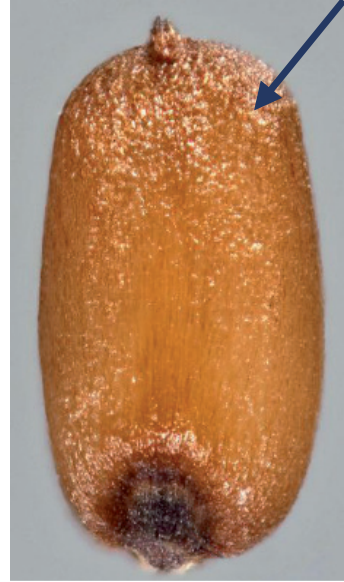

d

Figura 1. Alternativas de preparación de semillas de Cenchrus ciliaris L. De izquierda a derecha: fascículo intacto, fascículo escarificado, cariópside intacta, cariópside escarificada. Con línea punteada se indica el sitio de corte (fascículos) y el sitio de punción (cariópsides). 

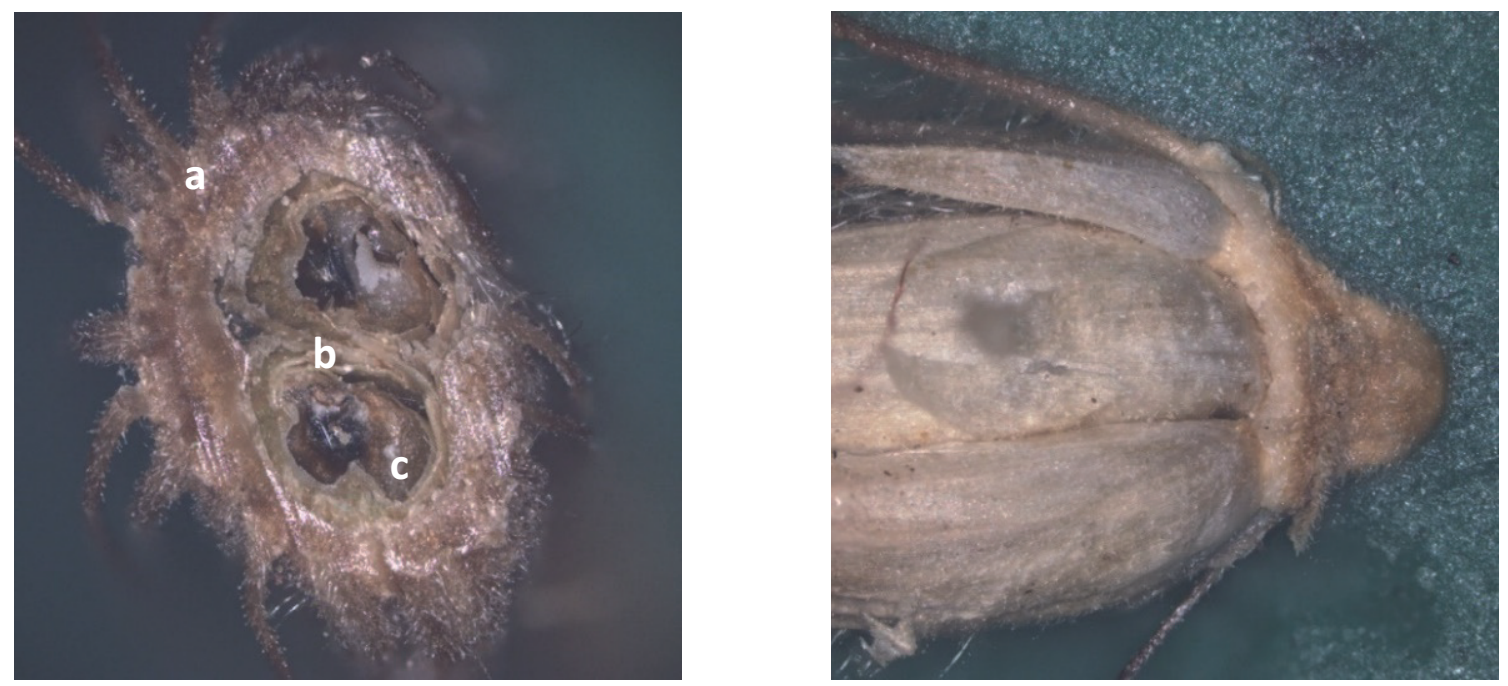

Figura 2. Izquierda: Corte transversal realizado en fascículos. a) Estructuras de protección del involucro (setas); b) glumas, lemmas y páleas; c) cariópside. Derecha: Espiguillas luego de ser retiradas las estructuras que forman el involucro.

Previamente a la realización de los análisis de germinación se determinó el porcentaje de fascículos llenos (\% LI) y el porcentaje de viabilidad por tetrazolio (Tz). Se procedió a integrar los resultados para una correcta expresión e interpretación de éstos.

El material tuvo los siguientes parámetros iniciales de calidad:

- Porcentaje de fascículos llenos (\% LI): 45\%

- Viabilidad por Tz de cariópsides: 85\%

- Viabilidad por Tz ajustada según el porcentaje de fascículos llenos: 38\%

Los valores de referencia mínimos establecidos por el Instituto Nacional de Semillas (INASE) para la comercialización de $C$. ciliaris L. para la República Argentina son: poder germinativo: 20\%; viabilidad por tetrazolio: $35 \%$.

Para confrontar los resultados obtenidos de fascículos y cariópsides, la germinación de estas últimas se ajustaron por el porcentaje de fascículos llenos. Así por ejemplo, valores de germinación del $20 \%$ en cariópsides, ajustados al porcentaje de fascículos llenos del lote (45\%) tuvieron una germinación del 9\%.

\section{Diseño experimental y análisis estadístico}

Para comparar las medias de los tratamientos se utilizó el análisis de la varianza. El modelo incluyó el factor tipo de semilla (fascículos, fascículos escarificados, cariópsides y cariópsides escarifi- cadas), el factor condición de germinación (testigo, pretratamiento frío, pretratamiento calor, nitrato de potasio, ácido giberélico) y la interacción entre ambos factores para un diseño completamente aleatorizado. Las comparaciones entre medias se realizó con la prueba DGC (Di Rienzo et al., 2002). El nivel de significación se fijó en 0,05 y para el análisis se utilizó el software InfoStat (Di Rienzo et al., 2015).

\section{RESULTADOS Y DISCUSIÓN}

\section{Siembra inmediata a cosecha. Sin almace- namiento}

A partir del conteo de plántulas normales, transcurridos 28 días desde la siembra y al determinar los porcentajes de germinación, se observó un aumento de los valores de germinación de cariópsides, cariópsides escarificadas y fascículos escarificados. En el análisis de la varianza se detectó interacción significativa entre los factores estudiados $(p=0,0025)$. Esto indicó que la respuesta en al menos una de las condiciones de germinación evaluadas dependió del tipo de semilla. Ante la interacción significativa, la comparación entre las medias permitieron diferenciar cuatro grupos; la conformación de cada grupo se presenta en la Figura 3.

El grupo A formado por cariópsides escarificadas tratadas con ácido giberélico tuvo 38\% de germinación, semejante a la viabilidad y considerando una tolerancia del 5\% (Franca Neto, et al. 1998). El 
grupo B de germinación entre 21 y 32\% incluyó a cariópsides escarificadas (testigo, frío, calor y nitrato de potasio), cariópsides (nitrato de potasio y ácido giberélico) y fascículos escarificados (ácido giberélico). El grupo C se integró de cariópsides (frío) y fascículos escarificados (testigo y frío) con 13 y $17 \%$ de germinación. Por último, el grupo D compuesto por fascículos sin escarificar cariópsides (testigo y calor) y fascículos escarificados (calor y nitrato de potasio).

Para explorar el comportamiento de cariópsides escarificadas que resultaron ser de mayor respuesta media, se promediaron valores de germinación de distintos tratamientos (testigo, frío, calor, nitrato de potasio y ácido giberélico) para cada tipo de material (Figura 4). La evolución del ensayo mostró que la germinación dependió del tipo de material utilizado. De esta forma, se observó que las cariópsides escarificadas lograron los mayores porcentajes (31\%), lo que prueba que existe un impedimento físico para la germinación en el pericarpio de las cariópsides. Distintos investigadores al escarificar cariópsides en pastos observaron el mismo comportamiento (Simpson, 1990). De acuerdo a Murdoch \& Ellis (2000) existe una clara asociación de los mecanismos de dormición al cariópside. Por otra parte, cariópsides y fascículos escarificados presentaron valores cercanos al 15\%. Mientras que los fascículos intactos no alcanzaron porcentajes superiores al $1 \%$ inclusive utilizando los pretratamientos para la ruptura de dormición recomenda- dos por las normas ISTA.

Los resultados de germinación en cariópsides escarificadas logrados fueron de 22 a 38\% tomando como valor de referencia la viabilidad del $38 \%$. Por lo tanto, los valores de germinación (sin ajustar) de 57 al 100\% demuestra que la escarificación en cariópsides promueve la germinación en C. ciliaris L. A diferencia de Parihar \& Pathak (2006) que obtuvieron $42-92 \%$ de germinación pero en cariópsides que provenían de un almacenaje de fascículos de 9 meses y que luego fueron desglumados.

\section{Tres meses de almacenamiento}

En este momento de análisis la interacción entre pretratamiento y tipo de semilla resultó no significativa $(p=0,1144)$. La Figura 5 muestra la evaluación correspondiente al día 28 y la influencia que tuvo cada tratamiento germinativo. El análisis indicó que independientemente del tipo de material utilizado los resultados más promisorios fueron con ácido giberélico. Alvarado et al. (2000) determinaron que el ácido giberélico actúa en la germinación de semillas de Solanum tuberosum L. por inducción de hidrolasas, enzimas que ablandan el endospermo facilitando la protrusión radicular. Por su parte, los tratamientos testigo, calor y nitrato de potasio alcanzaron valores de germinación entre 25 y $26 \%$. De las condiciones dadas a las semillas, el pretratamiento frío fue el menos efectivo y no alcanzó porcentajes superiores al mínimo comercial.

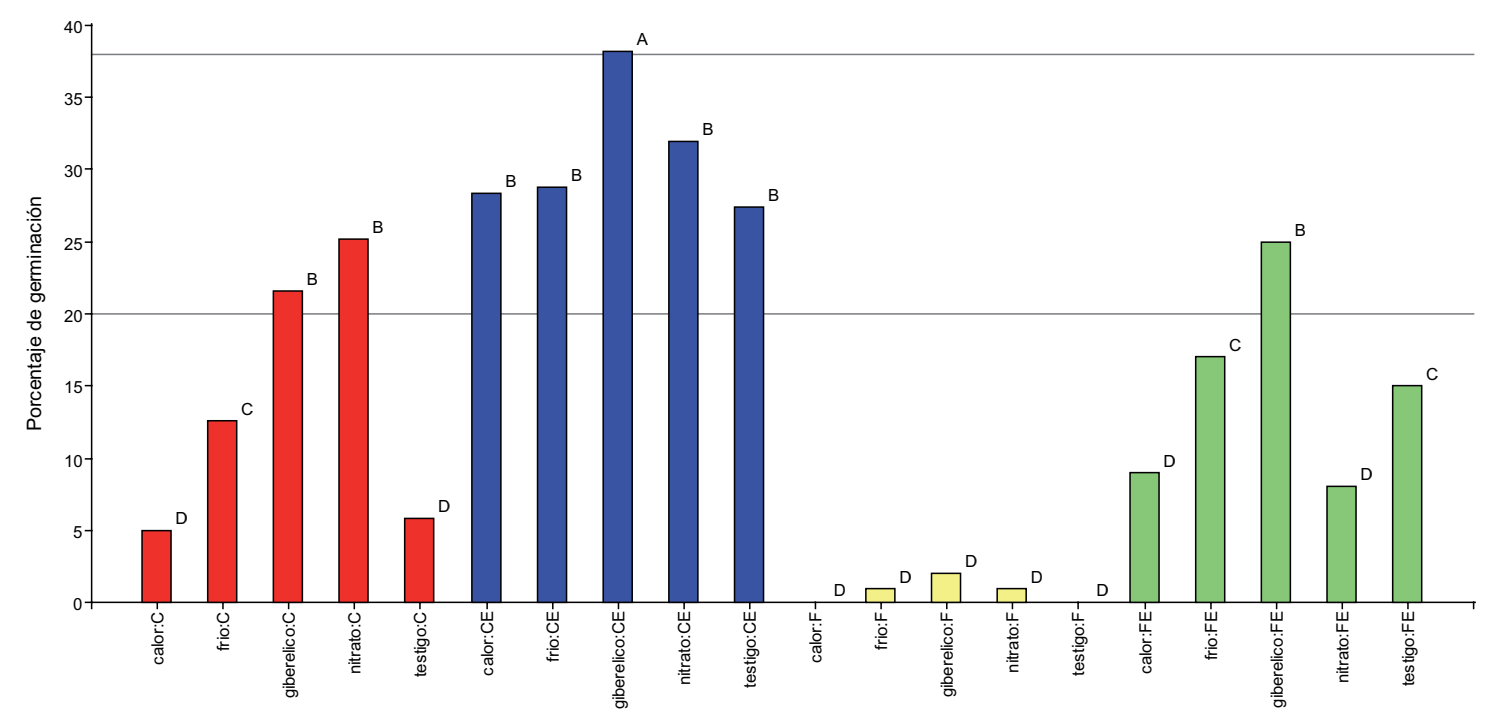

Figura 3. Grupos de germinación formados al día 28 por distintos tipos de materiales de Cenchrus ciliaris L. cultivar Texas sin almacenamiento. C: cariópsides (rojo); CE: cariópsides escarificados (azul); F: fascículos (amarillo); FE: fascículos escarificados (verde) y la aplicación en ellos de tratamientos germinativos (testigo; frío; calor; nitrato de potasio y ácido giberélico). Letras distintas indican diferencias significativas entre tratamientos $(p<0,05)$. 


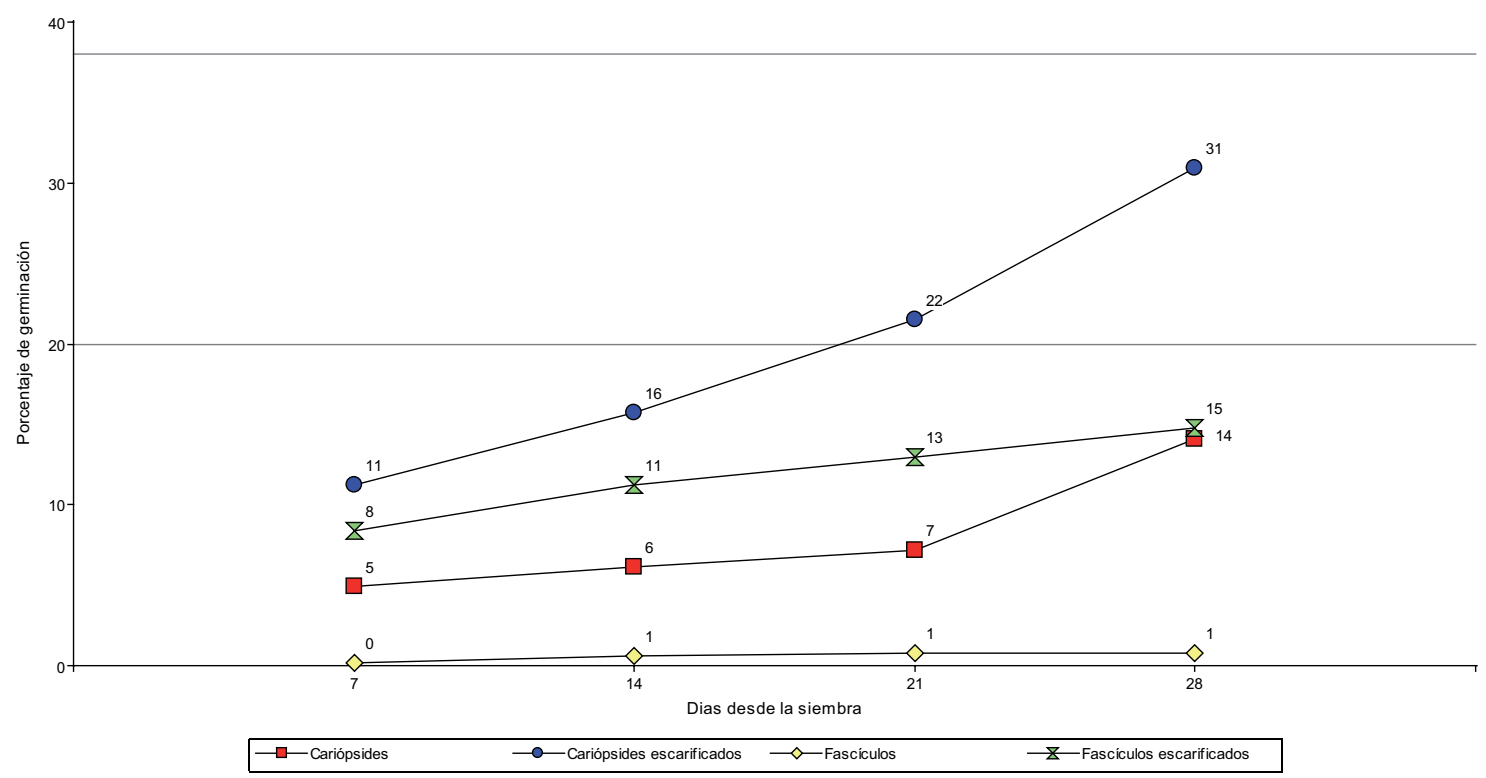

Figura 4. Curvas de germinación de Cenchrus ciliaris L. cultivar Texas sin almacenamiento. Cada material está constituido por el promedio de los pretratamientos germinativos aplicados a cada uno de ellos.

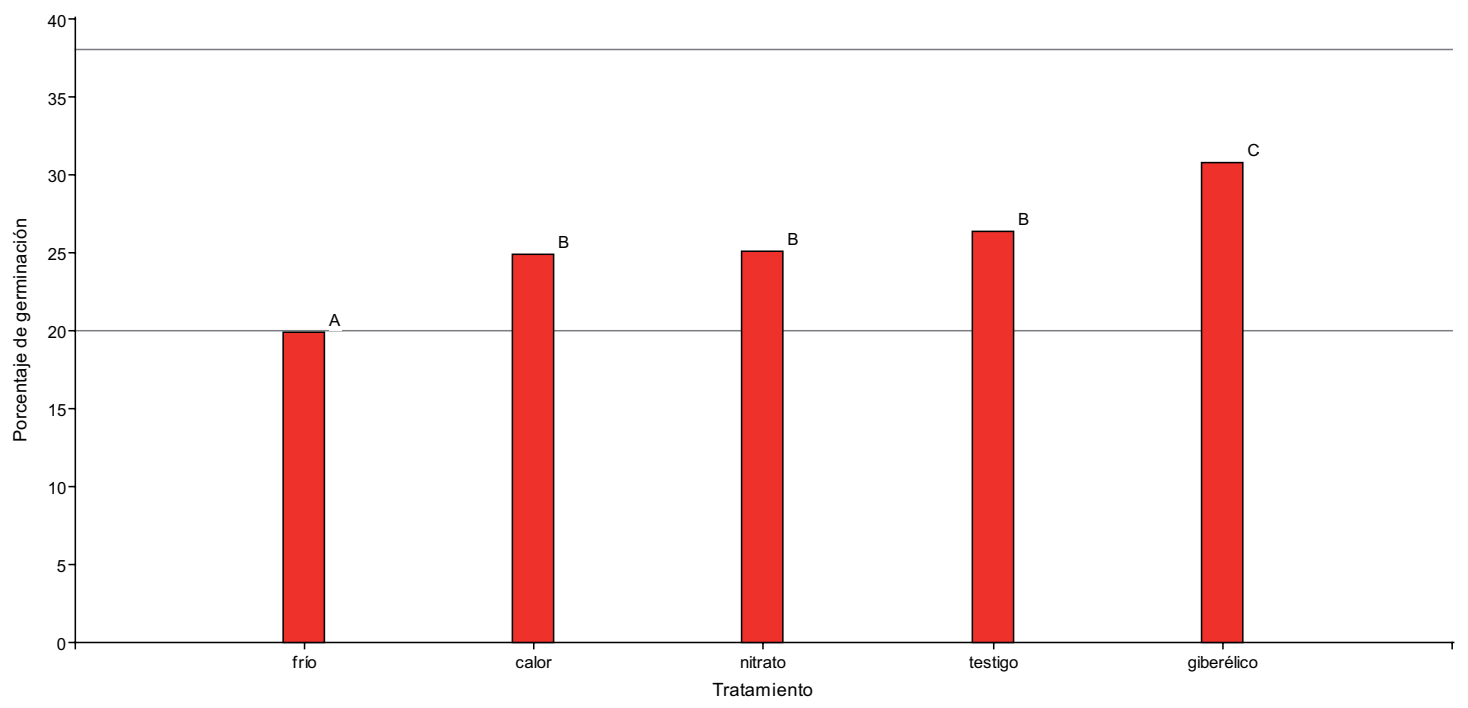

Figura 5. Porcentajes de germinación logrados en Cenchrus ciliaris L. cultivar Texas con 3 meses de almacenamiento al aplicar cinco tratamientos germinativos. Letras distintas indican diferencias significativas entre tratamientos $(p<0,05)$.

La Figura 6 muestra la performance de los distintos materiales. Las cariópsides con y sin escarificación alcanzaron el porcentaje de viabilidad superando considerablemente el estándar de comercialización. Los fascículos escarificados lograron superar el límite comercial pero quedaron distantes de la viabilidad estimada. Los fascículos intactos no tuvieron valores satisfactorios de calidad. El progreso de cada tipo de semilla se puede observar en la Figura 7.

\section{Seis meses de almacenamiento}

En estos ensayos se detectó interacción significativa entre los factores estudiados ( $p=0,0027)$ $y$, según las comparaciones entre las medias, se identificaron dos grupos. El grupo A de mayor ger- 


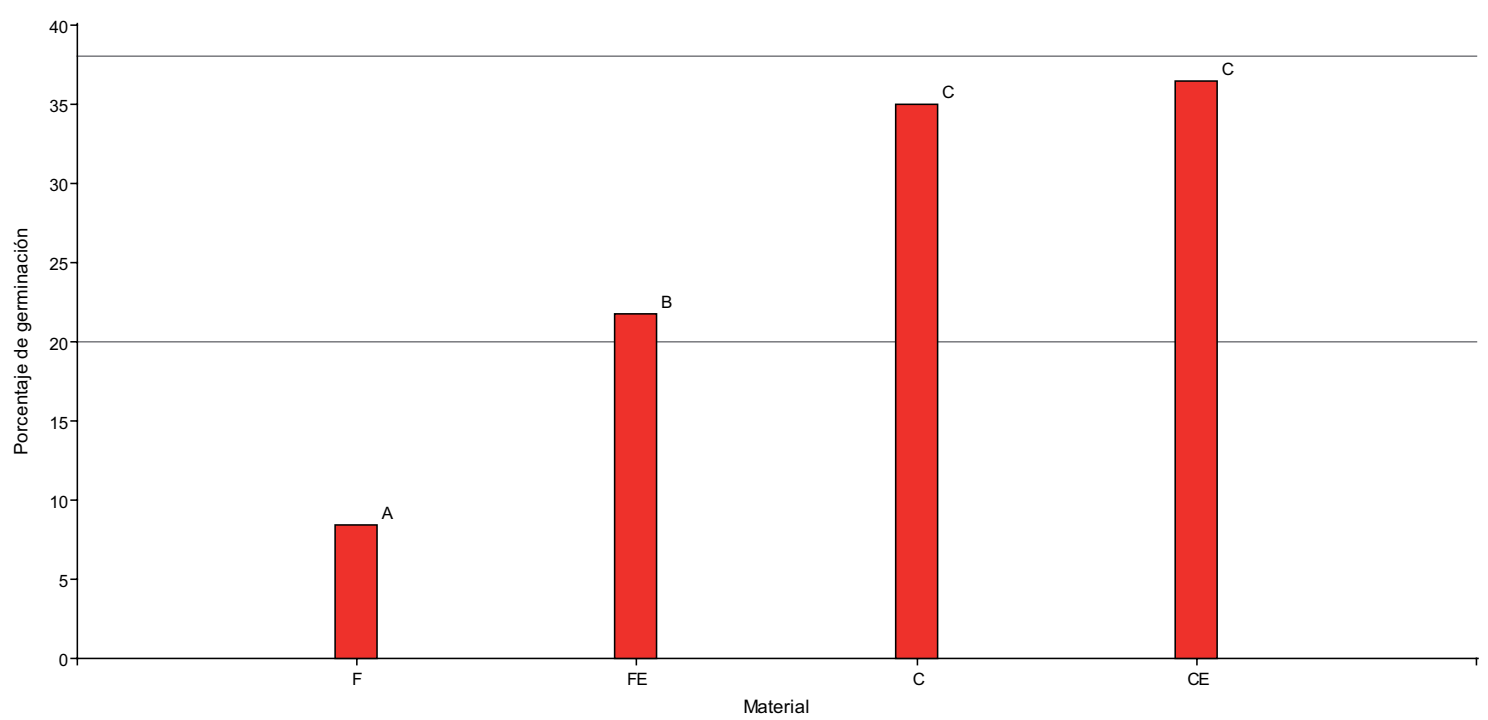

Figura 6. Porcentajes de germinación logrados en Cenchrus ciliaris L. cultivar Texas con 3 meses de almacenamiento al utilizar cuatro formas de preparación de las semillas. F: fascículos; FE: fascículos escarificados; C: cariópsides; CE: cariópsides escarificadas. Letras distintas indican diferencias significativas entre tratamientos $(p<0,05)$.

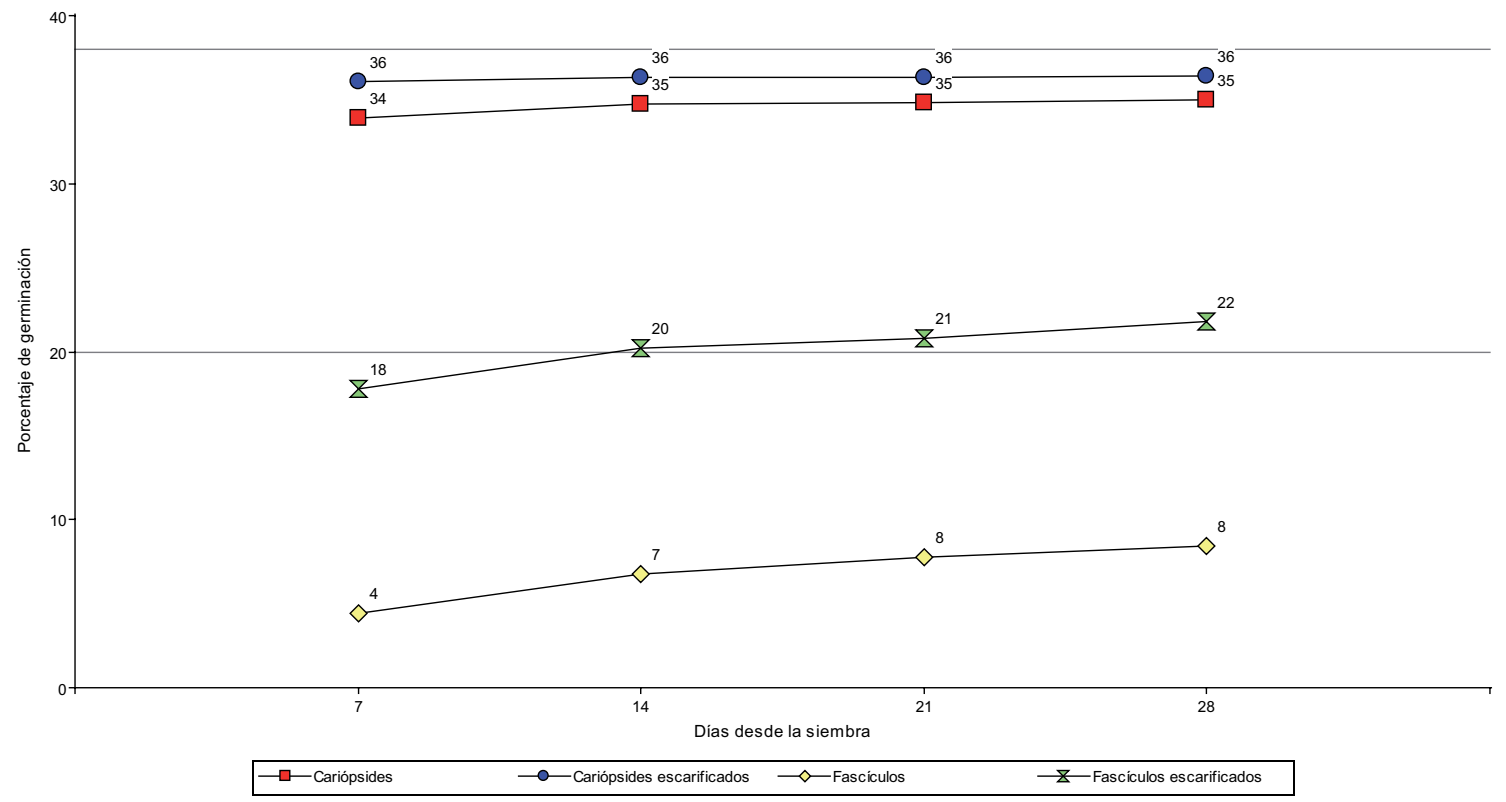

Figura 7. Curvas de germinación de Cenchrus ciliaris L. cultivar Texas con 3 meses de almacenamiento. Cada material está constituido por el promedio de los pretratamientos germinativos aplicados a cada uno de ellos.

minación (31-40\%) fue de cariópsides y cariópsides escarificadas para todos los tratamientos aplicados (testigo, frío, calor, nitrato de potasio y ácido giberélico). Los fascículos escarificados (testigo, nitrato de potasio y ácido giberélico) tuvieron un desempeño similar a los anteriores. El grupo B se constituyó con fascículos (testigo, frío, calor, nitrato de potasio y ácido giberélico) y fascículos esca- rificados (calor y frío), con porcentajes entre 11 y 21\% (Figura 8).

En la Figura 9 se observa un comportamiento similar de cariópsides respecto a los porcentajes de germinación alcanzados en los ensayos con 3 meses de almacenamiento. Los fascículos escarificados y fascículos intactos elevaron el porcentaje de germinación en un $6 \%$ respecto al momento de 


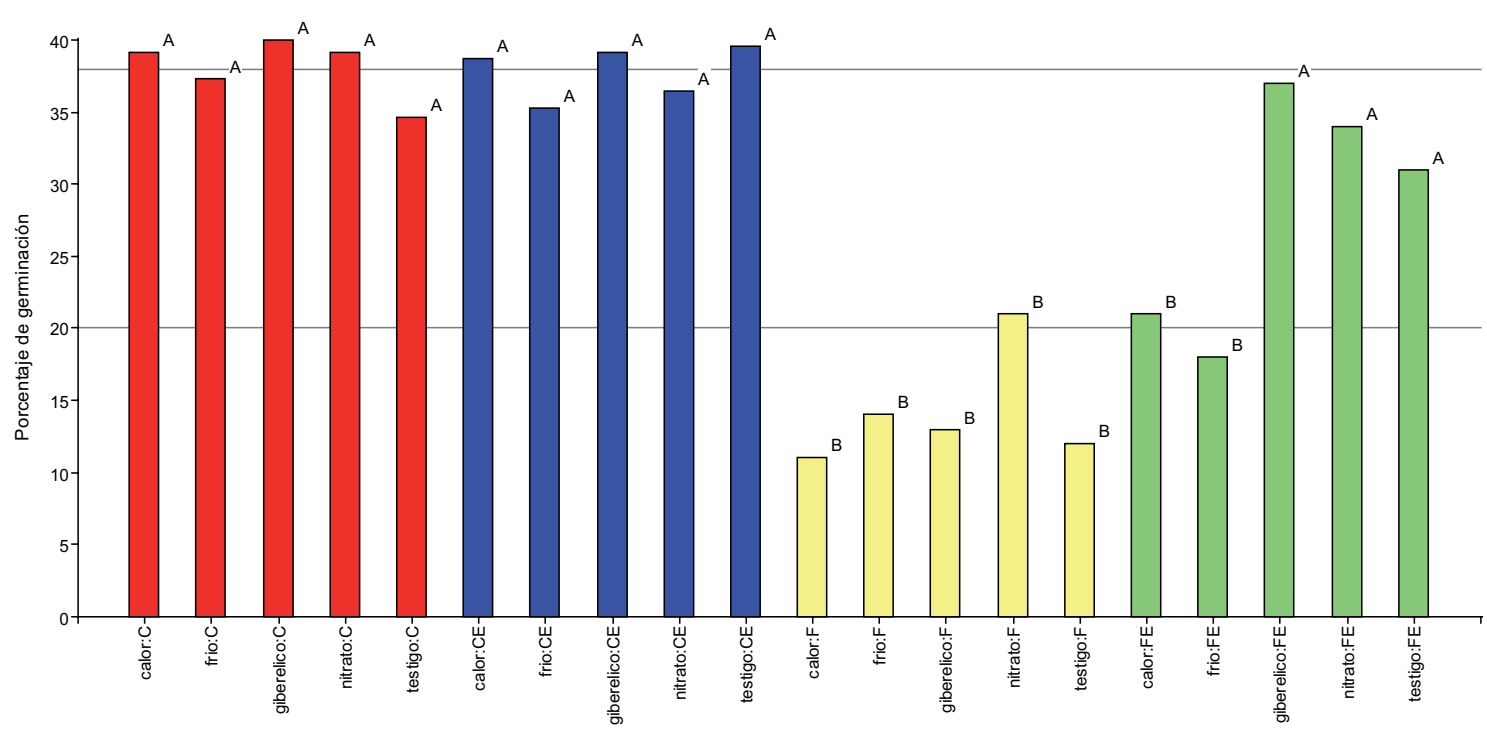

Figura 8. Grupos de germinación formados al día 28 por distintos tipos de materiales de Cenchrus ciliaris L. cultivar Texas con 6 meses de almacenamiento. C: cariópsides (rojo); CE: cariópsides escarificadas (azul); F: fascículos (amarillo); FE: fascículos escarificados (verde) y la aplicación en ellos de tratamientos germinativos (testigo; frío; calor; nitrato de potasio y ácido giberélico). Letras distintas indican diferencias significativas entre tratamientos $(p<0,05)$.

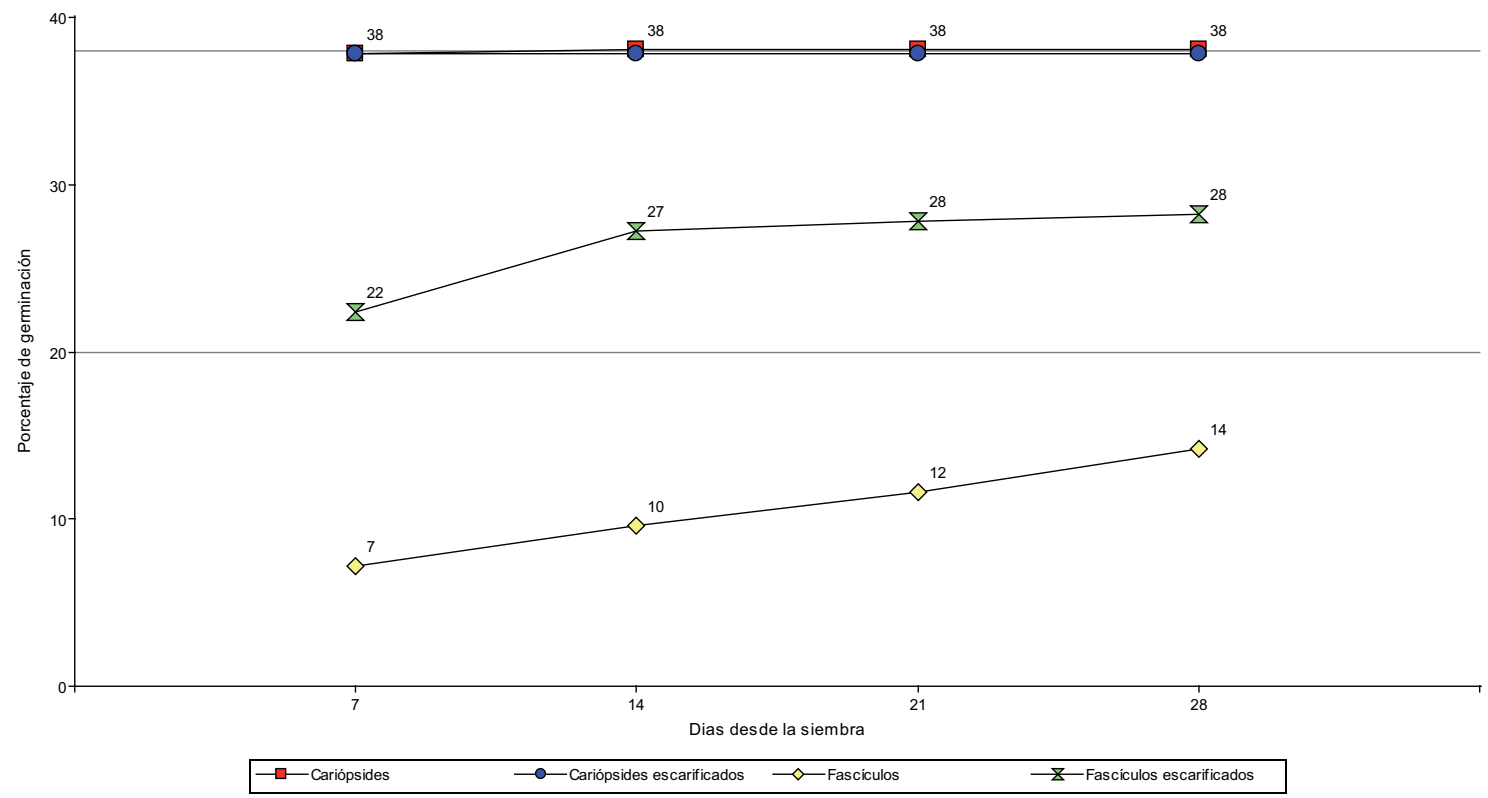

Figura 9. Curvas de germinación de Cenchrus ciliaris L. cultivar Texas con 6 meses de almacenamiento. Cada material está constituido por el promedio de los pretratamientos germinativos aplicados a cada uno de ellos.

análisis previo, pero sin alcanzar en el caso de fascículos intactos el mínimo para la comercialización.

En las evaluaciones correspondientes a los 3 y 6 meses las cariópsides alcanzaron en 7 días valores de germinación similares a la viabilidad; luego la germinación se estabilizó por la ausencia de semillas vivas que pudieran germinar. En cambio, los materiales correspondientes a fascículos mostraron un leve aumento durante el período ensayado, siendo la germinación de los fascículos sin escarificar menor a la germinación de los fascículos escarificados.

En fascículos escarificados los cortes eliminaron parcialmente la dormición al dañar las estructu- 
ras propias del involucro y/o al escarificar involuntariamente la/las cariópsides contenidas en ellos. Por esta razón, la germinación presentó en los tres momentos de evaluación valores superiores a los fascículos intactos, alcanzando en algunos casos porcentajes similares a las cariópsides. De acuerdo a Bewley \& Black (1982), las cubiertas ejercen influencias impidiendo la germinación. Es probable que la mayor germinación sea consecuencia de la apertura de vías de ingreso de agua, intercambio gaseoso e inclusive al ablandamiento de estructuras que ocasionan restricciones mecánicas. Según Loch (1993) la velocidad de germinación de las cariópsides es consecuencia del ingreso de agua en ausencia de las cubiertas de protección.

Simpson (1990) indicó la post maduración como un período clave para superar la dormición impuesta por las cubiertas seminales. En el caso de los fascículos intactos el impedimento se mantuvo inclusive después de ser almacenados durante 6 meses. La germinación observada en ellos fue gradual y creciente a través del tiempo, sin embargo, dichos materiales nunca lograron porcentajes germinación satisfactorios. En cariópsides el impedimento continuó en aquellas semillas con menos de 3 meses de almacenaje, el cual fue removido por medio de la escarificación y la utilización de ácido giberélico. Al observar los momentos de evaluación se observó que dicho mecanismo de dormición, situado en el pericarpio y propio de las cariópsides se pierde transcurrido un almacenaje en seco de al menos 3 meses. Este es el motivo principal por el cual la germinación de cariópsides intactas y de cariópsides escarificadas no presentó diferencias en las evaluaciones de los 3 y 6 meses. Parihar \& Pathak (2006) observaron que en pastos tropicales perennes el período de dormición varió entre 3 y 9 meses, y en $C$. ciliaris L. específicamente obtuvieron germinación satisfactoria luego de 9 meses de almacenaje.

En C. ciliaris L. se demostró la existencia de dos barreras que dificultan o impiden la germinación, una externa y otra interna. La más superficial constituida por el conjunto de estructuras que rodean al cariópside (involucro, glumas, lemmas y páleas) y la interna propia del cariópside. Tal como lo expresaron Bewley \& Black (1994) en semillas con dormición, para que el proceso de germinación ocurra, el impedimento que la impone debe ser removido o superado. De esta manera, la germinación de cariópsides fue mayor a la obtenida en fascículos como consecuencia de la eliminación de las cubiertas protectoras que dichas semillas poseen. Andersen (1953), Watson (1955), Loch (1993), Sharif-Zadeh \& Alistair Mordoch (2001) y Parihar \& Pathak (2006) observaron el mismo com- portamiento al experimentar con esta especie.

El estímulo en la germinación del pretratamiento con frío observado por Andersen (1953) y del pretratamiento con calor indicado por Brown (1952), Andersen (1953) y Butler (1985) no fue observado en este trabajo. Asimismo y de acuerdo con Butler (1985) no se detectaron estímulos al humedecer el sustrato de germinación con nitrato de potasio.

La presencia de inhibidores en las cubiertas, tal como expresaron Parihar \& Kanodia (1984) no se puede descartar debido a que no se realizó un estudio químico para corroborarlo. Sin embargo, la germinación de los fascículos escarificados, los cuales mantienen setas, glumas, lemmas y páleas en su lugar, sin eliminarlas, podría indicar la escasa participación en la dormición de las semillas.

En análisis realizados en laboratorio cuanto menor es la diferencia entre el valor de viabilidad por tetrazolio y el porcentaje de germinación logrado, tanto mejores serán las técnicas para cuantificar la calidad en semillas. Esto último indica, en $C$. ciliaris L. qué alternativa de preparación (material-semilla) es la más adecuada para superar la dormición y además el gran valor de estimación de semillas viables que posee la determinación de viabilidad por tetrazolio.

Según lo expresado por Baskin \& Baskin (2014) donde citan a $C$. ciliaris $L$. como una especie que posee dormición fisiológica (PD), se observó una clara influencia de las cubiertas seminales en la expresión de la dormición. Probablemente la gran variación de los resultados de distintos autores estén relacionadas a dos cuestiones básicas: no todas las unidades de dispersión (fascículos) contienen cariópside/s y que además, las cubiertas producen fluctuaciones en la expresión de la germinación.

De acuerdo a Hacker \& Ratcliff (1989), la procedencia de los materiales y las condiciones climáticas pueden tener una influencia importante en los atributos de dormición, por lo que se recomienda la determinación de fascículos llenos, la viabilidad por tetrazolio y la utilización de cariópsides en la germinación como herramientas fundamentales para una correcta determinación de la calidad en C. ciliaris $\mathrm{L}$.

\section{CONCLUSIONES}

Los resultados demostraron que los tratamientos para superar la dormición recomendados por las reglas ISTA (2012) no son lo suficientemente efectivos en semillas recién cosechadas de Cenchrus ciliaris L. En tal sentido, la utilización de 
cariópsides escarificadas y tratados con ácido giberélico en el período inmediato a la cosecha permitió obtener valores de germinación equivalentes a la viabilidad del lote. Con un almacenaje de 3 meses la utilización de cariópsides con y sin escarificación produjo los mejores resultados, por lo tanto no sería necesaria la escarificación en cariópsides, pero sí la ruptura de dormición con ácido giberélico. A los 6 meses el desempeño de las cariópsides fue muy bueno independientemente de los pretratamientos utilizados. De esta manera, se observó que el principal impedimento de la germinación es la presencia de barreras físicas que la dificultan, una externa formada por involucro, brácteas, glumas, lemmas y páleas y otra interna, propia de las cariópsides, ubicada en el pericarpio. Como generalmente no se conoce el tiempo de almacenamiento de las semillas la escarificación de cariópsides y la utilización de ácido giberélico son técnicas aconsejadas.

Para expresar adecuadamente los resultados de germinación obtenidos en cariópsides, de un lote de semillas compuestos por fascículos, se recomienda determinar el porcentaje de fascículos llenos y utilizarlo como factor de corrección.

\section{AGRADECIMIENTOS}

A la Ing. Agr. Margot Tablada y al Ing. Agr. Cristiano Casini por sus valiosos aportes para la realización del trabajo.

Al Ing. Marcelo De León por brindar el material vegetal utilizado en los ensayos.

\section{BIBLIOGRAFÍA}

Alvarado, V.; H. Hiroyaki and K.J. Bradford, 2000. Expression of endo- $\beta$-mannanase and SNF-related protein kinase genes in true potato seeds in relation to dormancy, gibberellin and abscisic acid. pp. 347-364.

Andersen, A.M., 1953. Germination of Buffel Grass Pennisetum ciliare (Link.) seed. Association of official Seed Analyst of North America Newsletter 27:36-37.

Baskin, J.M. and C.C. Baskin, 1989. Physiology of Dormancy and Germination in Relation to Seed Bank Ecology. Ecology of Soil Seed Banks. Academic Press Inc, pp. 53-66.

Baskin, J.M. and C.C. Baskin, 1998. Seeds: Ecology, biogeography, and evolution of dormancy and germination. San Diego. Academic Press, 666 pp.

Baskin, J.M.; C.C. Baskin and X. Li, 2000. Taxonomy, ecology, and evolution of physical dormancy in seeds. Plant Species Biology 15:139-152.
Baskin, J.M. and C.C. Baskin, 2004. A classification system for seed dormancy. Seed Science Research. 14:116.

Baskin, J.M. and C.C. Baskin, 2014. Seeds Ecology, Biogeography, and Evolution of Dormancy and Germination. Academic Press. San Diego, 1586 pp.

Bewley, J.D. and M. Black, 1982. Physiology and Biochemistry of Seeds in Relation to Germination. Viability, Dormancy and Environmental control. Berlin SpringerVerlag. Vol.2

Bewley, J.D. and M. Black, 1994. Dormancy and the control of germination. Seeds of development and germination. Ed. Plenum Press. New York and London, pp. 199-271.

Brown, E.O., 1952. Notes on germination of Buffel Grass. Association of official Seed Analyst of North America Newsletter, 26, 17.

Butler, J.E., 1985. Germination of Buffel Grass (Cenchrus ciliaris). Seed Science \& Technology. 13:583-591.

Clements, R.J. and D.J. Cameron, 1980. Collecting and Testing Tropical Forage Plants. Commonwealth Scientific and Industrial Research Organization. Melbourne, Australia, $154 \mathrm{pp}$.

Di Rienzo, J.A.; A.W. Guzmán and F. Casanoves, 2002. A Multiple Comparisons Method based on the Distribution of the Root Node Distance of a binary Tree. Journal of Agricultural, Biological, and Environment Statistics, 7 (2):1-14.

Di Rienzo, J.A.; F. Casanoves, M.G. Balzarini, L. Gonzalez, M. Tablada y C.W. Robledo, 2015. Grupo InfoStat, FCA, Universidad Nacional de Córdoba, Argentina. URL http://www.infostat.com.ar

Franca Neto, J.B.; F.C. Krzyzanowski y N.P.da. Costa, 1998. El test de tetrazolio en semillas de soja. Londrina. Embrapa. Brasil, $72 \mathrm{pp}$.

Hacker, J.B. 1989. The potential for Buffel Grass renewal from seed in 16-year-old Buffel Grass-siratro pastures in south-east Queensland. Journal of applied Ecology. 26: 213-222.

Hacker, J.B. and D. Ratcliff, 1989. Seed dormancy and factors controlling dormancy breakdown in Buffel Grass accessions from contrasting provenances. Journal of Applied Ecology. 26:201-212.

ISTA, 2009. International Seed Testing Association. Handbook on Seedling Evaluation. Third Edition. (Ed.) R. Don. Zürich.

ISTA, 2012. International Seed Testing Association. International Rules for Seed Testing. Seed science and Technology 31, Supplement. Zürich.

Loch, D.S., 1993. Improved handling of chaffy grass seeds; option, opportunities and value. Tropical Grasslands. 27:314-326. 
Murdoch, A.J. and R.H. Ellis, 2000. Dormancy, viability and Longevity. In, Fenner, M. (ed.), Seed: the ecology of Regeneration and Plant Communities. $2^{\text {nd }}$ edition, CAB International, Wallingford, Oxon UK, pp. 183-214.

Namur, P.T.; J. Tessi, R.E. Avila, H.A. Rettore y C.A. Ferrando, 2014. Buffel Grass: Generalidades, implantación y manejo para recuperación de áreas degradadas. Estación Experimental Agropecuaria La Rioja. INTA, 18pp.

Nikolaeva, G.M., 1977. Factors controlling the seed dormancy pattern. In: Kahan A.A. (ed.) Physiology and biochemistry of seed dormancy and germination, Elsevier/North Holland Biomedical Press, Holand, pp 50-73. Tomado de Camacho Morfin F., 1994. Dormición de semillas: Causas y tratamientos. Ed. Trillas, México, 125pp.

Parihar, S.S. and K.C. Kanodia, 1984. Seeds germination studies with Cenchrus sitigerus. II. Inhibition of seed germination by spikelet leachate and identification of inhibitors. Plant \& Nature 2:71-75.

Parihar, S.S. and P.S. Pathak, 2006. Flowering phenology and seed biology of selected tropical perennial grasses. Tropical Ecology 47(1) 81-87.

Pelton, J. 1952. A study of dormancy in eighteen species of high altitude Colorado Plants. Butler University botanical Studies. 18, (1).

Sendulsky, T.; T.S. Filgueiras and A.G. Burman, 1986. Fruits, embryos and seedlings. In Grass Systematics and Evolution, (Ed.) Soderstrom, T.R.; K.W. Hilu, C.S. Campbell and M.E. Barkworth, Washinston. D.C. Smithsonian Institute, pp. 31-36.

Sharif-Zadeh, F. and A.J. Mordoch, 2000. The effect of different maturation conditions on seed dormancy and germination of Cenchrus ciliaris. Seed Science Research 10: 447-457.

Sharif-Zadeh, F. and A.J. Murdoch, 2001. The effects of temperature and moisture on after-ripening of Cenchrus ciliaris seeds. Journal of Arid Environments 49:823-831.

Simpson, G.M., 1990. Seed dormancy in grasses. Department of Crop Science and Plant Ecology. University of Saskatchewan, Sasktoon, Canada, 297 pp.

Watson, C.E., 1955. Germination studies of Buffel Grass. Association of official Seed Analyst of North America Newsletter, 26, 17.

Werker, W.A., 1981. Seed dormancy as explained by the anatomy of embryo envelopes. Israel Journal of Botany 29: 22-44. 